\title{
The benefits of early valve replacement in asymptomatic patients with severe aortic stenosis
}

\author{
Morgan L. Brown, MD, ${ }^{\text {a }}$ Patricia A. Pellikka, MD, ${ }^{\mathrm{b}}$ Hartzell V. Schaff, MD, ${ }^{\text {a }}$ Christopher G. Scott, MS, ${ }^{\mathrm{c}}$

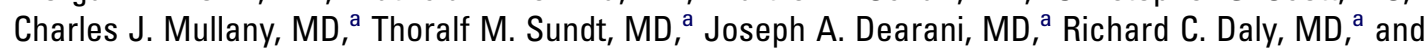 \\ Thomas A. Orszulak, MD ${ }^{a}$
}

Objective: The prevalence of aortic valve stenosis increases with age, and often the diagnosis is made by echocardiography before symptoms develop. To address the controversies in management of asymptomatic patients with severe aortic stenosis, we assessed the early and late outcomes of aortic valve replacement in these patients.

Methods: We analyzed data of 622 patients, aged $72 \pm 11$ years, with isolated asymptomatic severe aortic stenosis. Patients were identified with a peak systolic velocity of greater than $4 \mathrm{~m} / \mathrm{s}$ by transthoracic echocardiography and monitored for the development of symptoms and need for aortic valve replacement.

From the Divisions of Cardiovascular Surgery, ${ }^{\mathrm{a}}$ Cardiovascular Diseases, ${ }^{\mathrm{b}}$ and Biostatistics, ${ }^{\mathrm{c}}$ Mayo Clinic, Rochester, Minn.

Hartzell Schaff, MD, reports grant support from Carbomedics, St Jude Medical, and Medtronic.

Read at the Eighty-seventh Annual Meeting of The American Association for Thoracic Surgery, Washington, DC, May 5-9, 2007.

Received for publication May 3, 2007; revisions received Aug 17, 2007; accepted for publication Aug 23, 2007.

Address for reprints: Hartzell Schaff, MD, Mayo Clinic, 200 1st St SW, Rochester MN 55905 (E-mail: schaff@mayo.edu).

J Thorac Cardiovasc Surg 2008;135:308-15 $0022-5223 / \$ 34.00$

Copyright $\odot 2008$ by The American Association for Thoracic Surgery

doi:10.1016/j.jtcvs.2007.08.058
Results: After the initial diagnosis, 166 (27\%) patients who were initially asymptomatic experienced the development of chest pain, shortness of breath, or syncope and had aortic valve replacement at Mayo Clinic. Another 97 (16\%) patients had aortic valve replacement in the absence of symptoms. Symptomatic patients were more likely to undergo coronary bypass grafting $(P<.01)$ and have diabetes, hypercholesterolemia, and a lower ejection fraction $(P<.05$ for each). Operative mortality was $2 \%$ for symptomatic patients and $1 \%$ for asymptomatic patients $(P=.43)$. The survival of the 263 patients who underwent aortic valve replacement was not significantly different from an age- and sex-matched population $(P=.99)$; 10-year survival was $64 \%$ (95\% confidence interval [CI] 57\%-72\%) for symptomatic patients and $64 \%(95 \%$ CI $54 \%-75 \%)$ for asymptomatic patients $(P=.92)$. At 3 years after diagnosis of severe aortic stenosis, 52\% (95\% CI 48\%-56\%) of 622 patients had had symptoms develop, undergone aortic valve replacement, or died. Among the entire cohort, older age at diagnosis (hazard ratio [HR] 1.1 per year, $P<.001$ ), diabetes (HR 1.7, $P<.001$ ), decreased ejection fraction (HR 1.1 per $1 \% \downarrow, P=.01$ ), symptoms (HR 2.13, $P<.001$ ), and absence of aortic valve replacement (HR 3.53, $P<$ .001 ) were identified as independent risk factors for mortality.

Conclusion: Among patients with severe aortic stenosis who underwent aortic valve replacement, early and late outcomes were similarly good in patients who had symptoms before the operation compared with those who were asymptomatic. It is important to note that among patients with asymptomatic severe aortic stenosis, the omission of surgical treatment was the most important risk factor for late mortality.

I n 1965, McGoon, Pestana, and Moffitt ${ }^{1}$ wrote about aortic valve replacement (AVR), "Low hospital mortality tends to justify a policy of accepting patients for operation earlier in the natural progression of their disability, because it is recognized that there is a definite risk of rapid deterioration or sudden death in the earlier policy of deferring operation." Forty years later, management of asymptomatic patients with aortic valve stenosis (AS) remains a dilemma for cardiologists and surgeons. Traditionally, patients with asymptomatic severe AS are monitored expectantly until the development of symptoms because of the perceived low risk of sudden death. ${ }^{2}$ In these natural history studies, most patients were younger than those encountered by clinicians today and patients were more likely to have underlying bicuspid aortic valve disease. This approach also depends on satisfactory follow-up and prompt identification of the onset of symptoms. 


$$
\begin{aligned}
& \text { Abbreviations and Acronyms } \\
& \begin{aligned}
\mathrm{AS} & =\text { aortic stenosis } \\
\mathrm{AVR} & =\text { aortic valve replacement } \\
\mathrm{CI} & =\text { confidence interval } \\
\mathrm{HR} & =\text { hazard ratio }
\end{aligned}
\end{aligned}
$$

Decreasing surgical mortality for AVR and technological advancements in aortic valve prostheses argue for earlier surgical referral for most patients with aortic valve disease. A previous study of asymptomatic severe AS from the Mayo Clinic concluded that symptoms will develop within 5 years in most patients and that sudden death occurs at a rate of approximately $1 \%$ per year. ${ }^{3}$ In the present investigation, we compared late survival in patients with asymptomatic severe AS who were followed up medically versus patients who underwent AVR. In addition, we compared late outcomes of patients who had AVR in the presence of symptoms with those who remained asymptomatic at the time of AVR.

\section{Materials and Methods}

Approval for this study was granted by our institutional review board, and all patients gave written consent. We studied a cohort of 622 patients who had isolated asymptomatic $\mathrm{AS}^{3}{ }^{3}$ defined as a peak systolic velocity of $4 \mathrm{~m} / \mathrm{s}$ or greater by Doppler echocardiography. We excluded patients with any symptoms, age 40 years or younger, and those with multivalvular disease or moderate-to-severe aortic valve regurgitation. Other exclusion criteria included previous aortic balloon valvuloplasty, history of myocardial infarction, and prior coronary artery bypass grafting or percutaneous transluminal coronary angioplasty.

All 622 patients were entered into the study between 1984 and 1995 at the time of echocardiographic diagnosis of severe AS. Echocardiographic data included peak aortic valve velocity, aortic valve area, and the presence of left ventricular hypertrophy. As well, inactive status (assisted care) or active status (independent living) was recorded. After the initial diagnosis of severe AS, patients were ad- vised to return every 6 months to 1 year for re-evaluation. By reviewing of medical records, mailed questionnaires, and scripted telephone interviews, information regarding the development of cardiac symptoms, aortic valve surgery, and mortality were obtained for all patients. Death was confirmed by a death certificate or the Social Security Death Index.

Of the 622 patients initially identified, 297 had symptoms develop during follow-up (Figure 1), and 207 of these symptomatic patients underwent AVR. An additional 145 patients had AVR in the absence of symptoms. Of these patients who underwent AVR, 166 symptomatic patients and 97 asymptomatic patients had surgery at Mayo Clinic. This group of 263 patients had preoperative and intraoperative variables collected including a history of smoking, diabetes, hypercholesterolemia, renal failure (creatinine level $>2.0 \mathrm{mg}$ / $\mathrm{dL}$ ), hypertension, stroke, endocarditis, chronic lung disease, myocardial infarction, preoperative arrhythmia, preoperative ejection fraction, and cardiogenic shock. All preoperative and intraoperative characteristics were defined by The Society of Thoracic Surgeons Adult Database definitions.

Only patients who had AVR at the Mayo Clinic were included in the analysis of early and late operative outcomes because for these patients, all perioperative data were available. In the larger comparison of operative versus nonoperative groups, we included longitudinal data for all patients having surgery including those who had valve replacement at other institutions because vital status of all patients was known.

All statistical analyses were performed with SAS software (version 9.1.3; SAS Institute, Inc, Cary, NC). Data are summarized as means and standard deviations or frequencies and percentages. Groups were compared by $t$ tests and $\chi^{2}$ tests as appropriate. Survival was analyzed by the Kaplan-Meier method, and survival curves were compared by the log-rank test. Also, survival of patients after AVR was compared with that of the Minnesota population matched for age and sex and tested by the 1-sample log-rank test. Cox proportional hazards regression was used to identify variables independently associated with survival end points. Multivariate Cox models were formed by stepwise selection techniques. Estimated hazard ratios and $95 \%$ confidence intervals from models are presented.

To determine survivorship of all patients, we used the date of diagnosis of severe AS as time zero. Development of symptoms and

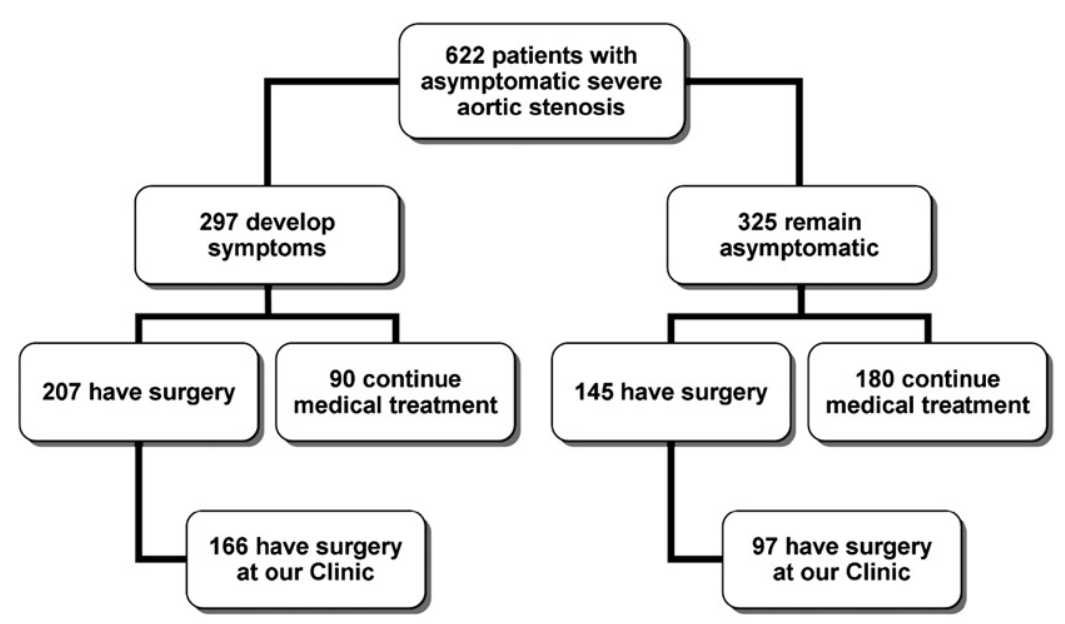

Figure 1. Follow-up of patients diagnosed with asymptomatic severe aortic stenosis. 
AVR were analyzed as time-dependent covariates in the Cox regression analysis. Figures showing survival for AVR and symptom groups were created by allowing patients to be in one or more of the curves. Patients were not allowed to be in multiple curves at the same time and could transfer into different curves on the basis of their AVR and symptom status at any time.

In the second analysis of only patients who had AVR, time zero was the date of surgery, and patients were censored if lost to followup. Cox models were used to predict late survival after the operation using patient characteristics at time of surgery.

\section{Results}

\section{Demographics}

Six-hundred twenty-two asymptomatic patients were identified by echocardiography as having severe AS. The mean patient age at diagnosis was $72 \pm 11$ years, and $384(62 \%)$ were men. The mean peak velocity was $4.4 \pm 0.4 \mathrm{~m} / \mathrm{s}$ and mean aortic valve area was $0.9 \pm 0.2 \mathrm{~cm}^{2}$. The mean ejection frac- tion was $64.3 \% \pm 7.3 \%$. For the entire group, follow-up averaged $7.8 \pm 5.3$ years. $^{3}$

Among these patients, 263 subsequently underwent AVR at Mayo, and the mean postoperative follow-up time was 9.1 years ( \pm 4.7 years). Comparing the asymptomatic and symptomatic patients who underwent AVR, there were no significant differences in age, gender, body mass index, and body surface area between the groups (Table 1) at the time of surgery. The mean length of time from diagnosis of asymptomatic severe AS to AVR was longer in the symptomatic patients $(2.38 \pm 1.7$ years vs $1.94 \pm 1.7$ years; $P=.04)$. Both aortic peak velocity and aortic valve area were similar in the two groups. Although most cardiovascular risk factors were not significantly different between asymptomatic and symptomatic patients, there was a higher prevalence of diabetes and hypercholesterolemia in the symptomatic patients.

In the symptomatic AVR group, there were significantly more patients who required concomitant coronary artery

TABLE 1. Demographics of patients at time of AVR

\begin{tabular}{|c|c|c|c|}
\hline Variable & Asymptomatic ( $\mathrm{n}=97$ ) & Symptomatic $(n=166)$ & $P$ value \\
\hline Mean age at surgery & $68.9 \pm 8.5$ & $71.1 \pm 10.5$ & .08 \\
\hline Male gender, No. (\%) & $60(62 \%)$ & $114(69 \%)$ & .26 \\
\hline Mean body mass index $\left(\mathrm{kg} / \mathrm{m}^{2}\right)$ & $26.7 \pm 3.8$ & $27.3 \pm 4.4$ & .22 \\
\hline Mean body surface area $\left(\mathrm{m}^{2}\right)$ & $1.91 \pm 0.2$ & $1.94 \pm 0.3$ & .37 \\
\hline Smoker, No. (\%) & $43(44 \%)$ & $72(43 \%)$ & .88 \\
\hline Diabetes, No. (\%) & $4(4 \%)$ & $21(13 \%)$ & .02 \\
\hline Hypercholesterolemia, No. (\%) & $30(31 \%)$ & $75(45 \%)$ & .02 \\
\hline Renal failure, No. (\%) & $3(3 \%)$ & $1(1 \%)$ & .11 \\
\hline Hypertension, No. (\%) & $49(51 \%)$ & $85(41 \%)$ & .91 \\
\hline Cerebral vascular accident, №. (\%) & $9(9 \%)$ & $9(5 \%)$ & .23 \\
\hline Infectious endocarditis, No. (\%) & $0(0 \%)$ & $4(2 \%)$ & .12 \\
\hline Chronic lung disease, No. (\%) & $5(5 \%)$ & $18(11 \%)$ & .12 \\
\hline Myocardial infarction, No. (\%) & $4(4 \%)$ & $12(7 \%)$ & .31 \\
\hline Cardiogenic shock, No. $(\%)$ & $0(0 \%)$ & $1(1 \%)$ & .44 \\
\hline IABP, No. (\%) & $2(2 \%)$ & $3(2 \%)$ & .88 \\
\hline Preoperative arrhythmia, №. $(\%)$ & $20(21 \%)$ & $44(27 \%)$ & .27 \\
\hline LVH by ECG, No. $(\%)^{*}$ & $19(20 \%)$ & $32(19 \%)$ & .95 \\
\hline Aortic valve area $\left(\mathrm{cm} / \mathrm{m}^{2}\right)^{*}$ & $0.87 \pm 0.2$ & $0.90 \pm 0.3$ & .50 \\
\hline Peak velocity $\left(\mathrm{m} / \mathrm{s}^{2}\right)^{*}$ & $4.37 \pm 0.4$ & $4.30 \pm 0.4$ & .14 \\
\hline Mean ejection fraction (\%) & $63 \pm 8.9$ & $60 \pm 12.5$ & .04 \\
\hline Tricuspid aortic valve, No. (\%) & $41(42 \%)$ & $104(63 \%)$ & $<.01$ \\
\hline Coronary bypass graft, №. (\%) & $26(27 \%)$ & $76(46 \%)$ & $<.01$ \\
\hline Mean cross-clamp time (min) & $58.8 \pm 23.2$ & $65.9 \pm 26.7$ & .03 \\
\hline Mean CPB time (min) & $86.4 \pm 33.5$ & $96.5 \pm 39.7$ & .04 \\
\hline Length of time to AS Dx at surgery & $1.94 \pm 1.7$ & $2.38 \pm 1.7$ & .04 \\
\hline \multicolumn{4}{|l|}{ Valve type } \\
\hline Bioprosthetic & $53(55 \%)$ & $83(50 \%)$ & \\
\hline Mechanical & $42(43 \%)$ & $73(44 \%)$ & .47 \\
\hline Homograft & $1(1 \%)$ & $7(4 \%)$ & \\
\hline Decalcification procedure & $1(1 \%)$ & $3(2 \%)$ & \\
\hline Operative mortality, No. (\%) & $1(1 \%)$ & $4(2 \%)$ & .43 \\
\hline
\end{tabular}

$A S$, Aortic stenosis; $A V R$, aortic valve replacement; $C P B$, cardiopulmonary bypass; $D x$, diagnosis; $E C G$, electrocardiogram; $I A B P$, intra-aortic balloon pump; $L V H$, left ventricular hypertrophy. ${ }^{*}$ Characteristics of patients at time of entry into study. 


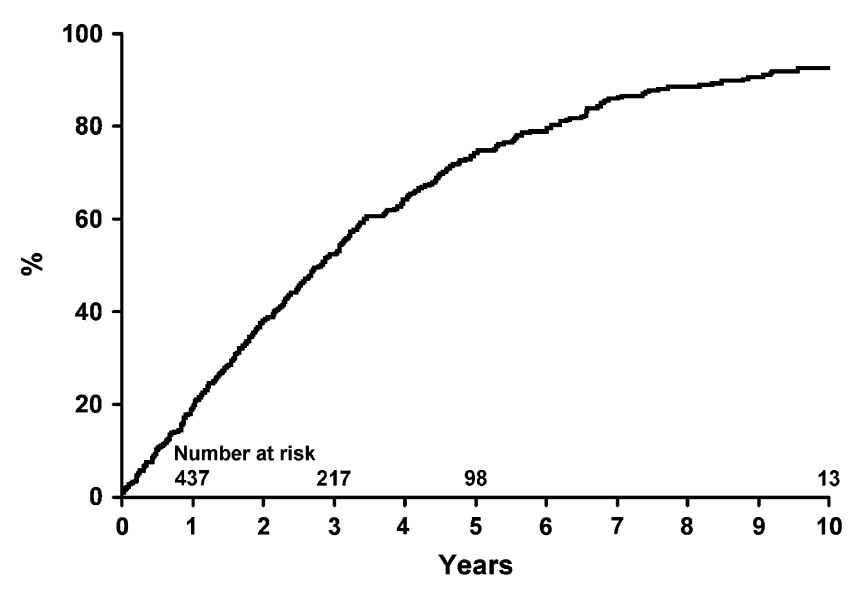

Figure 2. The probably of death, aortic valve replacement, or symptoms in patients diagnosed with asymptomatic aortic stenosis.

grafting, accounting for the longer cardiopulmonary bypass and crossclamp times. There were greater numbers of patients in the asymptomatic AVR group who had bicuspid or unicuspid aortic valves, whereas most patients had tricuspid aortic valves in the symptomatic group. In each group, there were similar proportions who received stented bioprosthetic, mechanical, and homograft replacement valves.

\section{Survival of Patients Stratified on Symptom Status and AVR}

After 3 years of follow-up, 52\% (95\% confidence interval [CI] 48\%-56\%) of 622 patients had had symptoms, had undergone AVR, or had died (Figure 2). Survival of all 622 patients who were originally given the diagnosis of asymptomatic severe AS is shown in Figure 3. Patients were also stratified into those who did and did not have symptoms and those who did and did not undergo AVR. Patients who had symptoms but did not have AVR had a 10-year survival of $2 \%$ (95\% CI 1\%-6\%). In patients who remained asymptomatic and did not have AVR, 10year survival was only $33 \%$ (95\% CI 24\%-45\%). In patient in whom symptoms developed and who had AVR, 10-year survival was 62\% (95\% CI 54\%-72\%), and in those who were asymptomatic but had AVR, survival was $70 \%$ (95\% CI 61\%-80\%). This analysis included all AVR patients, both those who had operation at Mayo and those who had operation elsewhere. By univariate analysis, an AVR in an asymptomatic patient was protective of late death by a relative risk of 0.38 (95\% CI $0.27-$ $0.55 ; P<.001)$. Among all 622 patients with asymptomatic severe AS, univariate predictors of mortality were older age at diagnosis, female gender, hypertension, diabetes, chronic renal failure, and symptom development (Table 2).

\section{Multivariable Predictors of Survival}

Older age at diagnosis, diabetes, inactive status, decreased ejection fraction, development of symptoms, and absence of AVR were all independent predictors of late mortality (Table 3 ).

\section{Survival After AVR}

Among patients who had AVR at Mayo, overall early mortality (within 30 days of surgery) was $2 \%$. There were more operative deaths among symptomatic patients (2\% vs $1 \%)$, but this small difference was not statistically significant $(P=$ .43). For all 263 patients undergoing AVR, regardless of symptom status, survival at 5 years was $85 \%(95 \%$ CI $81 \%-90 \%$ ), at 10 years, 64\% (95\% CI 58\%-70\%), and at 15 years, $36 \%$ (95\% CI 28\%-45\%) (Figure 4). When we stratified patients according to symptom status, there was no

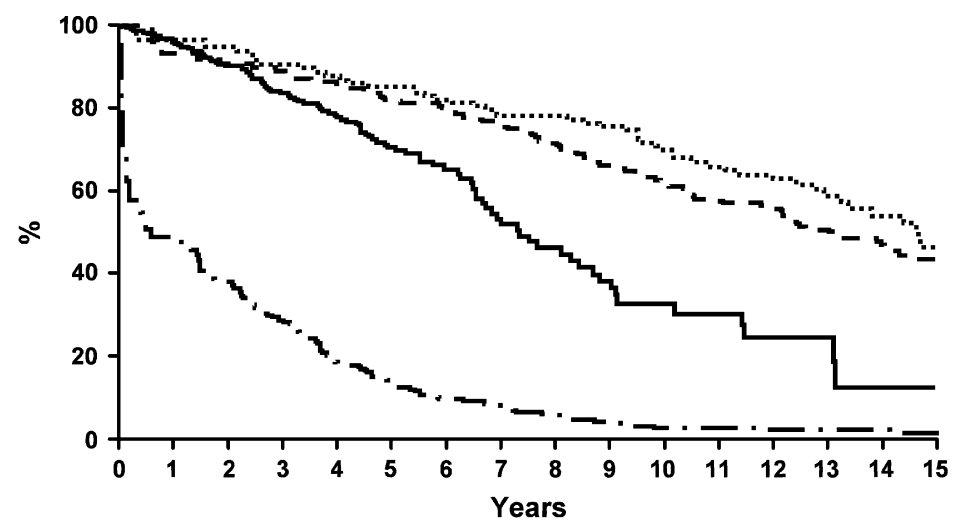

Figure 3. Survival of all patients diagnosed with asymptomatic severe aortic stenosis. AVR, Aortic valve replacement; sym, symptomatic.

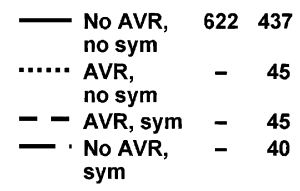

98

106

165

27

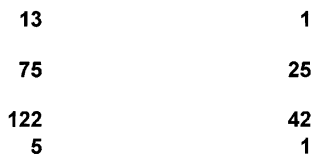


TABLE 2. Univariate predictors of late mortality in patients with a diagnosis of asymptomatic severe AS

\begin{tabular}{|c|c|c|c|c|}
\hline Variable & $\begin{array}{c}\text { Hazard } \\
\text { ratio }\end{array}$ & $\begin{array}{l}\text { Lower } \\
95 \% \text { CI }\end{array}$ & $\begin{array}{c}\text { Upper } \\
95 \% \text { Cl }\end{array}$ & $P$ value \\
\hline Age at echo & 1.086 & 1.073 & 1.099 & $<.001$ \\
\hline Male gender & 0.765 & 0.620 & 0.943 & .01 \\
\hline Hypertension & 1.253 & 1.020 & 1.540 & .03 \\
\hline Diabetes & 1.950 & 1.447 & 2.626 & $<.001$ \\
\hline Current or former smoker & 0.823 & 0.663 & 1.021 & .08 \\
\hline $\begin{array}{l}\text { Aortic valve velocity } \\
\quad \geq 4.5 \mathrm{~m} / \mathrm{s}\end{array}$ & 1.294 & 1.040 & 1.610 & .02 \\
\hline Chronic renal failure & 2.356 & 1.465 & 3.791 & $<.001$ \\
\hline Ejection fraction $(\uparrow 1 \%)$ & 0.985 & 0.970 & 1.001 & .06 \\
\hline Inactivity & 3.158 & 2.222 & 4.488 & $<.001$ \\
\hline Aortic valve area $\left(\mathrm{cm}^{2}\right)$ & 0.511 & 0.245 & 1.068 & .07 \\
\hline Time-dependent symptoms & 1.482 & 1.188 & 1.849 & $<.001$ \\
\hline Time-dependent AVR & 0.274 & 0.212 & 0.355 & $<.001$ \\
\hline
\end{tabular}

$A S$, Aortic stenosis; $A V R$, aortic valve replacement; $\mathrm{Cl}$, confidence interval. Only variables that had a $P$ value of $<.10$ were included in this table.

difference in late survival between patients who were symptomatic or asymptomatic at time of surgery $(P=.929)$ (Figure 5). Survival after AVR was compared with an ageand gender-matched Minnesota population, and there was no observed difference in late survival $(P=.99)$ (Figure 6). The last two figures include patients who had AVR at Mayo and elsewhere.

\section{Multivariate Predictors of Survival After AVR}

Independent predictors of mortality by multivariate analysis included increasing age (hazard ratio $[\mathrm{HR}]=1.10$ per year; $P<.001$ ), diabetes (HR $=1.91 ; P=.02$ ), previous myocardial infarction ( $\mathrm{HR}=2.50 ; P=.002)$, and previous cerebrovascular accident $(\mathrm{HR}=2.40 P=.002)$. Symptom status was not a predictor of late mortality $(\mathrm{HR}=1.24$; $P=.37$ ) on univariate or multivariate analysis.

\section{Discussion}

Because of the expanding elderly population, the prevalence of valvular disease is expected to double in the next 20 years. ${ }^{4}$

TABLE 3. Multivariate model predicting late mortality in patients with a diagnosis of asymptomatic severe AS

\begin{tabular}{lcccc}
\hline \multicolumn{1}{c}{ Variable } & HR & $\begin{array}{c}\text { Lower } \\
\mathbf{9 5 \%} \mathbf{C l}\end{array}$ & $\begin{array}{c}\text { Upper } \\
\mathbf{9 5 \%} \mathbf{C l}\end{array}$ & $\boldsymbol{P}$ value \\
\hline Age at diagnosis ( $\uparrow$ 1 year) & 1.07 & 1.056 & 1.083 & $<.001$ \\
Diabetes & 1.69 & 1.237 & 2.309 & .001 \\
EF $(\uparrow 1 \%)$ & 0.98 & 0.963 & 0.994 & $<.01$ \\
Time-dependent AVR & 0.28 & 0.210 & 0.381 & $<.001$ \\
Time-dependent symptoms & 2.13 & 1.664 & 2.735 & $<.001$ \\
\hline
\end{tabular}

$A S$. Aortic stenosis; $A V R$, aortic valve replacement; $C l$, confidence interval; $E F$, ejection fraction; $H R$, hazard ratio.

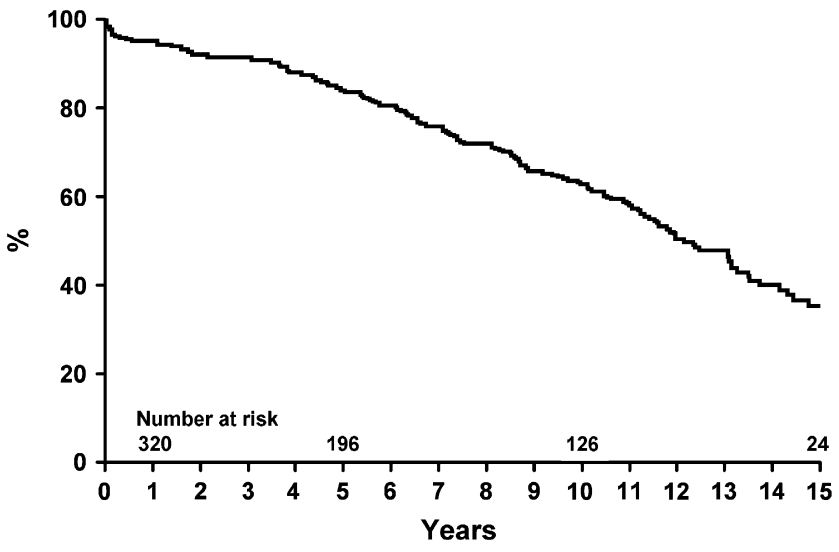

Figure 4. Survival after aortic valve replacement.

Studying an elderly population, Lindroos and associates ${ }^{5}$ reported a prevalence of $2.9 \%$ of severe AS. Thus, the decision about timing of operation in asymptomatic AS is likely to be encountered more frequently.

Some clinicians have suggested that earlier operation in asymptomatic patients with severe AS might improve late outcomes. Recently Pai and colleagues ${ }^{6}$ reported that survival benefit of AVR was independent of clinical, pharmacologic, and echocardiographic predictors. These authors recommended that the threshold for AVR in patients with severe AS should be lowered to include asymptomatic patients. ${ }^{6}$

In our study, all patients who underwent AVR had a survival advantage compared with that of patients who remained asymptomatic and did not undergo valve replacement. This suggests that all patients who have severe AS, symptomatic or not, would benefit from AVR. It is possible that some patients who were asymptomatic may have had symptoms develop and not told their physicians. Such patients may have been misclassified as asymptomatic, although it should be noted this is a potential hazard of "watchful waiting" and this cannot be assessed retrospectively.

We examined the last contact (survey, telephone, or in-person visit) in patients who eventually died while still asymptomatic; the average time from last contact to death was $1.7 \pm 2.1$ years (median 0.8 years), $37 \%$ had contact within 6 months of death, and 56\% had contact within 1 year of death. Although it is possible that closer followup may be beneficial, more than $50 \%$ of patients had been contacted within 1 year of their death. Thus, patients who are willing and have a reasonably low risk of operation should be offered early surgery.

It is unclear in this retrospective study as to why patients did not have an AVR in the presence of symptoms. Although some may have not been referred, many others were elderly and frail or had serious comorbidities such as cancer or dementia and refused surgery. 


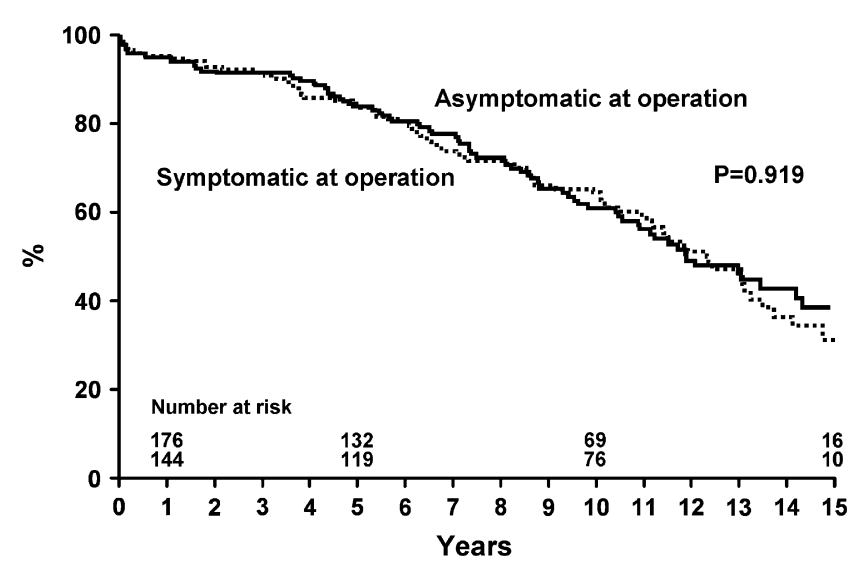

Figure 5. Survival after aortic valve replacement dependent on symptom status.

It would be advantageous to identify a "window" of time in which AVR can be safely postponed. However, when we examined the analysis of freedom from symptoms, surgery, or death in all 622 patients and censored patients at the time symptoms developed or surgery occurred, we could see no obvious "cut point" in our data. Instead, we found that at 3 years, approximately $50 \%$ of patients will have had symptoms develop, had AVR, or died.

Although patients who had AVR had clear survival benefit compared with that of patients not treated surgically, there was no apparent penalty for patients whose symptoms developed before surgery. In our study group, patients whose symptoms developed before AVR had similar long-term survival compared with patients who had surgery during their asymptomatic period. There was a trend toward a higher operative mortality in symptomatic patients $(2 \%$ vs $1 \% ; P=$ .43 ) but this did not reach statistical significance. The trend may be explained by higher prevalence of coronary artery disease reflected by the increased frequency of revascularization in this group (46\% vs $27 \% ; P=.002)$.

Some clinicians believe that patients who wait until the development of symptoms may have an increased operative and late mortality owing to a later stage of disease. In this series, patients were followed up regularly and were instructed to return if any symptoms developed. It should be noted that we had only 1 patient present for AVR in cardiogenic shock. If there had been a greater number of patients requiring emergency AVR in the symptomatic group, we may have seen an advantage to intervention when patients were still asymptomatic. $^{7}$ Further, it is possible that benefits of earlier operation may be more apparent in patients with longstanding AS who have complications such as severe left ventricular hypertrophy.

Previously, some cardiologists advised "cat-like observation" for asymptomatic patients with severe AS because of

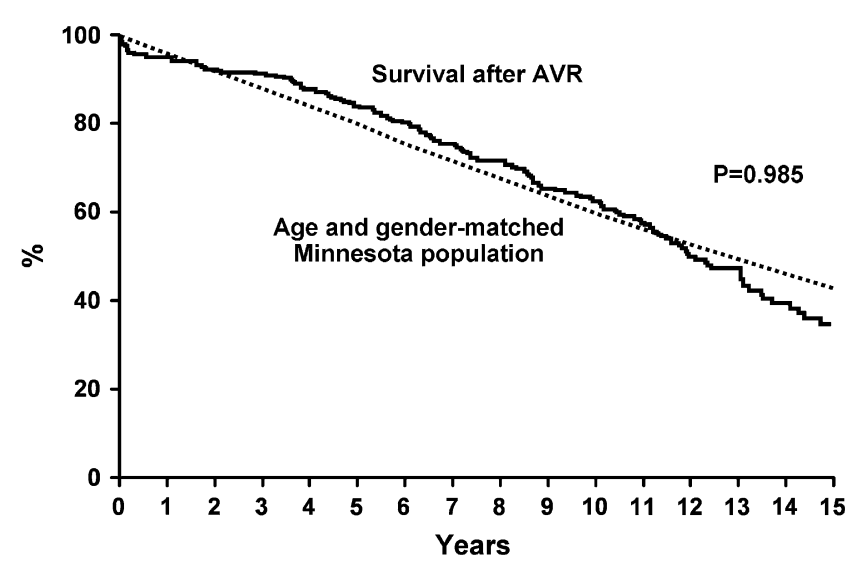

Figure 6. Survival after aortic valve replacement (AVR) for severe aortic stenosis compared with age- and gender-matched Minnesota population.

the anticipated $2 \%$ to $3 \%$ yearly risk of prosthesis- and anticoagulant-related complications and the $1 \%$ yearly incidence of death after AVR. ${ }^{8,9}$ However, when patients who had received an AVR in our series were compared with an ageand gender-matched Minnesota population, there was no difference in late survival, suggesting that the risk of aortic valve prostheses-related complications and death may be overestimated with the use of modern mechanical valves that require lower anticoagulation levels and bioprosthetic valves that have greater durability.

In this study, the unadjusted surgical mortality for AVR in asymptomatic patients was $1 \%$, and although asymptomatic patients with severe AS may constitute a relatively low-risk surgical group, some caution must be exercised when generalizing our results. The Society of Thoracic Surgeons National Adult Cardiac Surgery Database reports an unadjusted mortality for isolated AVR of $3.5 \%$ and $5.6 \%$ for combined AVR and coronary artery bypass grafting. ${ }^{10}$ The survival benefit of AVR in patients with asymptomatic severe AS may apply only to centers that have sufficient volume of valve surgery so as to maintain very low operative mortality. ${ }^{11}$

Otto $^{12}$ and others ${ }^{13}$ suggest risk stratification of patients with AS who do not have obvious symptoms using exercise testing and measurement of brain natriuretic peptide. Other identified risk factors for poor outcomes in patients with asymptomatic AS include velocity of jet, rate of change of jet velocity, functional status, and extent of aortic valve calcification. ${ }^{14,15}$ Unfortunately, there was no attempt to systematically risk-stratify patients in our study cohort. Sensitive and objective measures of symptom development may be beneficial to identify those patients who would gain the most from early surgical intervention. 
Previous generations of cardiologists have advocated medical management of severe AS until symptoms are well established. It was stated in a recent editorial, "We, like most cardiologists, no longer believe that surgery is the most common cause of sudden death in asymptomatic patients with aortic stenosis." 16 Results of the present study support the idea of early intervention in patients with a diagnosis of severe asymptomatic AS when there is a low institutional perioperative mortality. It is possible that future studies that include risk stratification will improve patient selection for AVR.

\section{Conclusions}

At 3 years, $52 \%$ of asymptomatic patients with severe AS had symptoms develop, had AVR, or had died. Patients with severe AS who present without symptoms do not have greater operative and long-term mortalities if they undergo elective AVR after the development of symptoms. Importantly, however, patients who had symptoms and patients who remained asymptomatic and had AVR had a survival advantage when compared with asymptomatic patients who had medical management alone.

\section{References}

1. McGoon DC, Pestana C, Moffitt EA. Decreased risk of aortic valve surgery. Arch Surg. 1965;91:779-86.

2. Ross J, Braunwald E. Aortic stenosis. Circulation. 1968;38(1 Suppl): 61-7.

3. Pellikka PA, Sarano ME, Nishimura RA, Malouf JF, Bailey KR, Scott CG, et al. Outcome of 622 adults with asymptomatic hemodynamically significant aortic stenosis during prolonged follow-up. Circulation. 2005;111:3290-5.

4. Nkomo VT, Gardin JM, Skelton TN, Gottdiener JS, Scott CG, EnriquezSarano M. Burden of valvular heart disease: a population-based study. Lancet. 2006;368:1005-11.

5. Lindroos M, Kupari M, Heikkila J, Tilvis R. Prevalence of aortic valve abnormalities in the elderly: an echocardiographic study of a random population sample. J Am Coll Cardiol. 1993;21:1220-5.

6. Pai RG, Kapoor N, Bansal RC, Varadarajan P. Malignant natural history of asymptomatic severe aortic stenosis: benefit of aortic valve replacement. Ann Thorac Surg. 2006;82:2116-22.

7. Mullany CJ. Aortic valve surgery in the elderly. Cardiol Rev. 2000;8: 333-9.

8. Vaile JC, Griffith MJ. Management of asymptomatic aortic stenosis: masterly inactivity but cat-like observation. Heart. 1997;78:215-7.

9. Vongpatanasin W, Hillis LD, Lange RA. Prosthetic heart valves. N Engl J Med. 1996;335:407-16.

10. Fall 2006 STS Executive Report. http://www.sts.org/documents/pdf/ STS-ExecutiveSummaryFall2006-REVISED.pdf. Accessed March 19, 2007.

11. Birkmeyer JD, Stukel TA, Siewers AE, Goodney PP, Wennberg DE, Lucas FL. Surgeon volume and operative mortality in the United States. N Engl J Med. 2003;349:2117-27.

12. Otto CM. Valvular aortic stenosis: disease severity of timing of intervention. J Am Coll Cardiol. 2006;47:2141-51.

13. Amato MC, Moffa PJ, Werner KE, Ramires JA. Treatment decision in asymptomatic aortic valve stenosis: role of exercising testing. Heart. 2001;86:381-6.

14. Otto CM, Burwash IG, Legget ME, Munt BI, Fukioka M, Healy NL, et al. Prospective study of asymptomatic valvular aortic stenosis. Circulation. 1997;95:2262-70.
15. Rosenhek R, Thomas B, Porenta G, Lang I, Christ G, Schemper M, et al. Predictors of outcome in severe asymptomatic aortic stenosis. $N$ Engl J Med. 2000;343:611-7.

16. McCann GP, Hillis WS. Surgery in asymptomatic aortic stenosis. BMJ. 2004;328:63-4.

\section{Discussion}

Dr Michael A. Acker (Philadelphia, $\mathrm{Pa}$ ). This paper is very important. I believe its import lies not in the extraordinary low mortality, for which the Mayo cardiac surgeons are to be congratulated, but rather in this very careful observation of the natural history of asymptomatic AS and also the similarities in the operative mortality between the asymptomatic and symptomatic patients undergoing AVR. I have three questions, which I will ask one at a time to give you a chance to answer.

Although you showed overall survival and benefit for just getting the valve replaced, $50 \%$ of your patients remained asymptomatic without AVR and without death at 3 years. Did you look at this group to determine preoperative characteristics such as the presence of left ventricular hypertrophy, for instance, that would be predictive of a benign course so that we do not have to operate on everyone who has severe AS?

Dr Brown. We did not specifically look at that group of patients. However, in a previous study, both a smaller aortic valve area and left ventricular hypertrophy predicted symptom development in patients with asymptomatic AS.

Dr Acker. Second question: As you know, the operative mortality across the country for AVR and aortic valve and coronary bypass surgery, according to The Society of Thoracic Surgeons database, is not $1 \%$ and $2 \%$ but rather $3.5 \%$ for AVR alone and nearly $6 \%$ for an AVR/coronary bypass. It is thus imperative, if one is considering operating on the asymptomatic patient, to know the true operative result. On the other hand, to complete that risk/benefit analysis, one would have to know the rate of sudden death if we are going to wait in the asymptomatic group and the factors that would predict sudden death. Do you have some information on that?

Dr Brown. I cannot help you with the factors that will predict sudden death; however, I can tell you that the rate of sudden death in this cohort was approximately $1 \%$ per year. As you can see, with an operative mortality of $1 \%$, it is a reasonable decision to operate in these patients.

Dr Acker. Finally, did you look at the need for coronary bypass surgery or the ischemic burden as an independent risk factor for the development of symptoms or long-term survival?

Dr Brown. Again, we did not specifically look at patients who did or did not have coronary artery bypass grafting except for in our multivariate model.

Dr Paul Kurlansky (Miami, Fla). You demonstrated very nicely that AVR was an independent risk factor for lower mortality, but obviously both in the symptomatic and the asymptomatic patients, the decision not to operate was based on many factors. Did you use propensity analysis or any other method to try to match patients who did not have surgery with patients who did have surgery to see whether you could discern other independent factors that would have led to the decision not to operate?

In other words, it would seem as though merely waiting and watching is not necessarily a wise decision, but that is not necessarily the decision that was made. The decision not to operate may have been a conscious one based on other risk factors that may 
themselves have been predisposed to mortality. Therefore, the decision not to operate is really a surrogate for other factors. I was wondering whether you used any statistical method to try to explore this.

Dr Brown. No, we did not use any type of statistical methods such as propensity matching. The problem is that trying to identify retrospectively why patients did not have surgery is always difficult, and as mentioned, our beliefs are that there are several reasons. Some patients are not referred, some patients are elderly and frail and do not wish to have surgery, and some patients, of course, have cancer or dementia, which may preclude an invasive procedure.

Dr Wade L. Knight (Temple, Tex). I noticed from the summary in the book that you did not include anyone in your group with an ejection fraction less than $40 \%$. Admittedly, that makes your statistics look better in your outcomes, but I think what those of us in the audience need to know is what do the real life group of patients look like? Many of the people that might have been turned down for surgery may have been turned down because of low ejection fractions or high creatinine values. You are probably familiar with the article in the December 2006 issue of The Annals of Thoracic Surgery, I think out of Loma Linda, addressing the large percentage of patients with AS turned down or never referred for aortic valve surgery. At your institution, did you refuse AVR for patients with ejection fractions less than $40 \%$, or did you just not include them in this report?

Dr Brown. Just to make it clear, of the original cohort of patients who were identified with asymptomatic AS, only $3 \%$ had an ejection fraction of less than $50 \%$. We did not specifically exclude any patient simply for having a low ejection fraction in our surgical series.

Dr Ahmed El Gamel (London, United Kingdom). The question of mortality from your paper is quite clear: you have a low operative mortality. However, one question that bothers me is the morbidity of replacing a valve in a patient who is asymptomatic. Complications like stroke, even if it is a minor one, will make the patient stay in the hospital for a period of time. Have you any feeling of how much morbidity the asymptomatic patients have experienced and how long the hospital stay was for patients who needed readmission for any complications after surgery?
Dr Brown. We do not look at specific data on the length of stay after surgery. As was shown, the mortality after surgery is similar to that of an age- and gender-matched population. However, you are correct; we did not specifically look at the burden of morbidity in a patient who receives an AVR.

Dr Christopher M. Feindel (Toronto, Ontario, Canada). When determining whether patients have symptoms or not, was there consistency in obtaining a good history? I know that sounds pretty basic, but I think if you question patients you will often pick out symptoms that, believe it or not, even the cardiologist might not pick up.

Dr Brown. This study stretched over a long period of time, beginning in 1984, and there was no systematic objective assessment such as an exercise stress test. However, a cardiologist did review all these patient charts to determine that this was an actual asymptomatic patient.

Dr A. W. Atkinson (Raleigh, NC). I think it is an interesting study and it is sort of a negative study. It shows that symptoms do not really predict the outcome of surgery. You would think otherwise, that the more symptomatic patients are going to have a little tougher time or a higher mortality, but that is not true. It seems that it is very subjective, and I think we need to be much more definitive. We have seen this with mitral valve disease; lots of asymptomatic people's ventricles are deteriorating. It has been my impression that people are fairly asymptomatic, but a lot of these people are not very active. They do not do a whole lot and the biggest thing in their life is to get surgery. We really need more objective criteria than just how the patient feels according to a telephone call or when they visit the doctor. When they are afraid of surgery, they are not going to have many symptoms. I think we need numbers like Bonow's mitral valve data, as someone mentioned, left ventricular hypertrophy, pulmonary artery pressures, left atrial size, presence or absence of atrial fibrillation. There are a whole lot of criteria that we need to put on these patients and see what they have, when they have it, do they have it, and then I think we will have a lot more sorting out as to when we need to operate on these patients. 